\title{
Crafting Authenticity: An Ethnography of Conservation Practice
}

\author{
Siân Jones and Thomas Yarrow
}

\begin{abstract}
This paper explores how authenticity is produced through different forms of expertise and skill, as they are negotiated and aligned in the daily practices of conservation. Focusing on the traditional craft practices of stonemasons, we trace out their relations to the broader nexus of experts responsible for conserving Glasgow Cathedral. We show that authenticity is a distributed property of distinct forms of expert practice, as they intersect with one another, and, crucially, with the material conditions of specific heritage sites. It is argued that, in the context of conservation practice, authenticity is neither a subjective, discursive construction, nor a latent property of historic monuments waiting to be preserved. Rather it is a property that emerges through specific interactions between people and things.
\end{abstract}

Keywords: heritage, conservation, authenticity, stonemasonry, policy, practice, expertise

On a sunny day in August 2010 tourists approach the south door of Glasgow Cathedral, passing swathes of scaffolding (Figure 1). Commercial guides shepherd large groups quickly by, while other visitors pause to examine display boards explaining Historic Scotland's conservation programme. The message is one of threat and redemption: set against a history of damage and decay, state-sponsored work preserves the monument for future generations. Central to this vision is the work of the stonemasons (Figure 2). Ghosted medieval prints signify continuity of craftsmanship, an idea made explicit in the text: 'like medieval craftsmen, today's masons use hand tools to maintain the Cathedral'. Images of Historic Scotland's masons underscore these ideas, emphasizing the skilled, painstaking nature of their craft. At the back of the Cathedral, this work can be encountered in action, as two masons steadily remove a piece of medieval masonry. Shielded from the tourist gaze, in the Monument Conservation Unit Yard on the north side of the Cathedral, three masons are cutting new indents of stone to replace the decayed originals.

These scenes suggest that preserving this nationally significant, medieval building for posterity is a straightforward process. Natural and human threats have taken their toll and the building needs conserving to secure the past for the future. Some stones are so decayed or fractured they need to be replaced wholesale. Masons, embodying 'traditional skill', preserve the past for future generations. Yet, as those involved acknowledge, this picture masks a complex and fraught process. The replacement of even apparently insignificant pieces of masonry is framed by national and international policies. These require careful consideration of physical condition and cultural significance, which in turn involves a range of different actors with different kinds of expertise and skilled practice. Ultimately what is at stake is the authenticity of the building and the evidence it embodies, something that is fundamental to the theory and philosophy of conservation. 
One of the chief aims of heritage conservation is to safeguard monuments for future generations, preserving them as far as possible in their authentic form. Protection and preservation with minimum intervention are emphasized in international heritage charters and conventions (e.g. ICOMOS 1964; ICOMOS 1979 [1999]) and national policies (e.g. Historic Scotland 2000, 2001, 2009). Yet even 'minimum intervention' entails modification that potentially threatens authenticity and erases evidence. Until recently, conservation theory and practice has been dominated by a positivist approach, which ultimately takes the existence of the object of conservation as given (Villers 2004: 4-5). Within this framework, historic value and authenticity are seen as intrinsic characteristics inherent in the material fabric of the object (Bell 2011: 225; Brajer 2011: 84; Jones 2010: 184). In a romantic vein, this has long been associated with the hallowed notion of the 'historic witness' that material fabric bears to the origins of monuments and their continuity through time (Eggert 2009: 26-28). More recently a growing battery of scientific techniques have been used in an attempt to verify this intrinsic authenticity through material analysis (Clavir 2002; Villers 2004). Regardless of these subtle differences, much is therefore at stake in any physical intervention involving the removal and replacement of material fabric. The issue for practitioners is how to retain the past that is embodied by buildings and monuments, while interventions necessary for their preservation require material change in the present (Philipott 1996: 270; also Muñoz Viñas 2011; Pye 2006). In practice, as Pye (2006) discusses, unremitting choices must be made about what can be changed or lost and what must stay 'the same'. Yet while conservation policies offer a set of universal framing principles, the values they contain radically under-determine the specific interventions that may emerge in response to any given situation (Yarrow 2011). Ongoing practices of translation and mediation are therefore required, involving various forms of expertise.

Understanding of these practices has been undermined by a gulf that opened up between conservation and the direction of cultural theory in the late 1960s (Eggert 2009; Jones 2010). Those influenced by cultural theory set about dismantling some of the central tenets of heritage conservation, in particular the idea that 'evidence' and 'authenticity' are inherent, objective attributes of historic objects. Instead, it has been argued that both are constructs of the present, products of particular cultural contexts and specific regimes of meaning (e.g. Holtorf and Schadla Hall 1999; Lowenthal 1992). Yet, in the process heritage conservation has been rendered a relatively undifferentiated discursive nexus, flattening out the diverse forms of expertise and skilled practice involved. In the last decade, conservation professionals have responded, engaging in their own exploration of the subjective, contingent and historically situated nature of conservation, but at the same time highlighting the complex range of processes involved (e.g. Bracker and Richmond 2011; Clavir 2002; Muñoz Viñas 2011; Pye 2006; Villers 2004). Some, like Brajer (2011), explore the complexity of practices relating to key concepts like authenticity in specific areas, such as the conservation of wall paintings. Others, such as Clavir (2002) and Eggert (2009), seek to develop new foundations for conservation based on theories that bring significance, agency and time to the fore leading to approaches that are attentive to the complex processes of producing and consuming historic objects, monuments, works of art and literature. Thus, conservation is increasingly recognized as a complex process, playing an active, and at times decisive, role in the life of an object, building or monument (Pye and Sully 2007). Nevertheless, the ethnographic complexity of the practices involved in heritage 
conservation remains relatively poorly understood, in particular with respect to how different forms of expertise and skill coalesce to produce specific material interventions.

In this article, we explore how the paradoxes of securing the past while changing it are dealt with in the daily practices of heritage conservation. We seek to illuminate the networks of materials, actors and actions involved in conserving historic buildings and monuments. In recent work on architecture, scholars drawing on Actor Network Theory have challenged the idea that buildings are stable, discrete objects, arguing that they are the result of perpetual processes of making and re-making (Jacobs and Merriman 2011; Strebel 2011). They show that these processes enjoin a complex array of agencies ranging from algal films to large-scale weather events, from original architects to those who maintain and live in buildings, including animal inhabitants (e.g. Edensor 2011). Within this framework, conservation emerges as an important sphere through which buildings and monuments are actively made and unmade. For instance in their study of post-war conservation and regeneration in Exeter, Tait and While (2009) show how specific views, buildings and streets are sustained and sometimes dismantled over time. Emphasizing materiality, Edensor (2011) similarly highlights how practices of maintenance and repair stabilize St Anne's Church in Manchester, while simultaneously transforming its original form and fabric.

Our research builds on this work, emphasizing how the authenticity of historic buildings and monuments emerges through the relational negotiation of specific forms of expert practice, as they intersect with one another in and through specific material contexts. From an ethnographic perspective, we extend the insights of Edensor (2011) and Tait and While (2009), revealing how conservation actors navigate networks of relationships with other actors and materials. In particular, we show how conservation actors themselves highlight and negotiate the paradoxes and contingencies involved in the application of conservation policies. Our focus is Glasgow Cathedral (Figure 3), currently undergoing a long-term programme of repair and maintenance implemented by a team of skilled stonemasons. Since the mid-nineteenth century, traditional arts and crafts have played a central role in conservation. For Ruskin (1865) and others, the authenticity and 'living spirit' of historic buildings depended on regular maintenance using traditional craftsmanship. Yet while conservation discourses continue to underscore the importance of 'traditional crafts' (Historic Scotland 2001), the work of stonemasons now intersects with that of other experts, including curators, managers and conservation scientists. Rather than approach conservation as a matter of socially constructed 'meaning', we examine how different kinds of expert practice interact with, shape, and define the Cathedral as a heritage object. In particular, we draw on Annemarie Mol's (2002) concept of 'enactment'. From this perspective, different experts do not simply provide different forms of knowledge about a stable object: diverse skilled practices literalize different kinds of material object. We seek to illuminate how these practices, and the different visions of the Cathedral that attend them, are negotiated and aligned in the context of specific physical interventions.

As the only mainland Scottish cathedral surviving the Reformation relatively intact, Glasgow Cathedral is subject to various conservation measures, including designation as both a Category A listed building and a scheduled ancient monument. Scheduling is restricted to the sub-surface remains of the Cathedral, because it is an ecclesiastical building in use, whereas the listing status applies to the above ground 
building. The Cathedral is also owned by Scottish Ministers and in the care of Historic Scotland (hereafter HS), the government agency with responsibilities for Scotland's historic environment. As Bell (2011: 226) argues, such designation incorporates buildings and monuments into a national built 'archive' that must be preserved, curated, and interpreted. Our analysis is based on collaborative fieldwork conducted during the summer of 2010 with members of HS's Monument Conservation Unit based at the Cathedral. We carried out participant observation with the masons, producing close observations of their work. Apprenticeship was not part of our research, although we were introduced to basic cutting techniques. 'Directed conversation' took place in the context of participant observation. Qualitative interviews and building tours were also recorded with each of the masons, and others involved in the protection and management of the Cathedral. These included architects from HS's Conservation Group, responsible for assessing its condition and devising and overseeing conservation strategies, as well as those dealing with access and understanding at properties in HS's care. In particular, those in the Cultural Resources Team, many of whom have an archaeological background, played a prominent curatorial role, defining the cultural significance of the monument. HS underwent major re-structuring following our fieldwork, and some of the roles and organizational structures we refer to have changed since 2010. Nevertheless, the practices we discuss remain central to HS's conservation approach, and shed light on a broader set of dynamics underpinning the enactment of internationally recognized conservation principles in a range of institutional and historic contexts.

\section{Assessing condition, defining significance}

In the Cathedral conservation yard, two masons and the young apprentice are at work. Angus is cutting a replacement for a decayed nineteenth-century finial capping one of the gable buttresses (Figure 4) (pseudonyms are used throughout). John is contemplating the practice head he is carving in preparation for a new gargoyle, which will replace a severely decayed, structurally compromised medieval one. Now and again he interrupts his studied reflection to comment on the apprentice's work, as he cuts his first ashlar indent. Their work appears self-contained, but the limits of this independence are quickly revealed. Another mason arrives in the yard and, over a late tea break, airs his frustrations over the limited extent of the work. 'If that's badly worn away, it should be replaced', says Doug, 'you've got big areas [of indented stringcourse] running along and then you come across one or two old ones [...] Why didn't they just [let us] replace them as well?' Meanwhile, Ally arrives and ascends the stairs to the Squad Manager's office to clarify how far he should extend his work raking out and repointing cementitious mortar used in a Victorian conservation campaign. Architect's drawings of the Cathedral highlighting areas designated for work are taped to the walls of Alek's office. The bookshelves are overflowing with architectural guides, health and safety manuals, and other reports. The extent to which the masons' work is framed and contained by a wider network of relationships with other heritage professionals is thus revealed in the material conditions of the yard.

The Cathedral conservation project, initiated in 1998, will take about 30 years to complete. It consists of a comprehensive programme of consolidation and repair, including indenting (replacement) of masonry and selective re-pointing (Figure 5). Minimum intervention is emphasized and indenting is only recommended in cases 
where decaying masonry compromises structural integrity or exacerbates weathering of surrounding masonry. Catherine, a senior manager responsible for issues of public understanding and access at HS properties, highlights how these activities are shaped by a venerable tradition of international charters and conventions:

The current policy is based on all of that international movement. It's about saying what you have in the building is the evidence of the past that can go on informing you and if you tinker with that you change it.

Nevertheless, conservation instruments and policies provide guidelines and principles that in their generality necessarily underdetermine what should happen at specific sites. Susan, a senior member of the Conservation Group in HS, explains: 'finding a way to establish what's good and what's not is very difficult. It's in the policies, but it's never pinned down actually, because it's got to be varied between different sites.' Thus, broad conservation principles have to be translated into concrete proposals.

Since the nineteenth century, when conservation activists, notably Ruskin and Morris, reacted against enthusiastic restoration, minimum intervention has been upheld as an ideal and is central to international conservation instruments (e.g. ICOMOS 1964; ICOMOS 1979 [1999], 3). Accordingly, Scotland's Historic Environment Policy (SHEP) also takes it to be a central principle, which informs the work of all those involved in the conservation of monuments in HS's care. Yet, while retention of evidence and authenticity is emphasized, policies must balance this overriding ideal with recognition that some changes may be unavoidable or even desirable (Muñoz Viñas 2011; Pye 2006). Thus SHEP acknowledges that conservation of 'historic character' has to be balanced against recognition that 'everything changes, matures and decays' (HS 2009: 5). Mitigation of the resulting jeopardy focuses on a combination of understanding, significance and evidence. Historic buildings are seen as 'documents' embodying evidence. If their fabric is threatened, the resulting interventions must be based on evidence and a thorough understanding of significance (see Bell 1997).

As with other monuments in the care of HS, an Interim Statement of Cultural Significance has been produced for Glasgow Cathedral (HS 2005a). This draws on historical and archaeological research, which reveals phases of construction and allows earlier material to be differentiated from later modifications and additions. Though only fragments of the earliest phases survive, significance nonetheless derives from the close association with St Kentigern (Mungo), the patron saint and founder of the city of Glasgow. The thirteenth-century form of the building is also attributed great significance, as 'one of the most ambitiously planned cathedrals in scale and quality of architecture' and 'the only mainland cathedral to have survived the aftermath of the reformation without major structural loss' (ibid: 5). Social values are also identified including its role as a setting for artistic and civic activities, a focus of community life and a venue for national events. Aesthetically it is seen as 'an imposing and dignified presence', and spiritually 'many people continue to hold the ongoing patronage of the saint to be real, in both religious and secular terms' (ibid: 4).

'Significance' thus emerges as a composite of intersecting values (Clavir 2011). Taken together these index the building's national importance and justify statesponsored conservation work. The concept of significance also enables assessment of 
the relative value of different aspects of the building and therefore facilitates prioritization. In this case, the history of the building and its architectural contributions are privileged aspects of its significance (HS 2005a: 5-6), deemed to be intrinsic to the building (cf. Bell 2011: 225; Tait and While 2009: 723). In particular, the 'completeness of the plan' allows a visitor 'to connect with the experience of the medieval pilgrim' (HS 2005a: 6). The statement of significance thus makes various forms of evidence 'readable', whilst simultaneously elevating some over others. It provides a framework through which judgements can be formed and specific interventions negotiated in response to the physical condition of the building.

'Condition surveys', in contrast, provide an assessment of the physical fabric of monuments based on close visual inspection by conservation architects, accompanied by an overview of the monument's historical development prepared by a member of the Cultural Resources Team. In marked contrast to the statement of significance, material condition is documented in exhaustive detail. For instance, for the East Choir Chapels, the latest condition survey for Glasgow Cathedral (2005b) records:

Buttresses are in fair condition with only limited stone indents required to the weathered back [...] Close inspection revealed very weathered string courses at exposed corner buttresses. Many of the corbels in corbel table [are] powdering (exfoliating) to a degree that little bearing left for tabling course supporting parapet. (HS 2005b: 98)

However, the measured, meticulous process of assessing the physical state of the building is not enough in itself to licence intervention. Judgements must be made about the extent of the repairs that require the statement of significance to be mobilized. Since the Cathedral's significance is principally attributed to its medieval fabric, greater attention is given to these elements. Thus, when the corbels mentioned above were replaced extensive efforts were made to distinguish the surviving medieval ones from the Victorian restorations so that new indents could be modelled on the former. Furthermore, while the overall form and design of the Victorian architectural elements are valued, greater emphasis is placed on their aesthetic aspects than their historic fabric. Susan, a conservation architect by training, makes this explicit:

Some of the areas we were looking at, there was so much renewed [Victorian] stone, there was no huge cultural significance in the individual stones; it was more about making a nice smooth wall again because it needed to [be like that] as a piece of architecture.

The relatively low level of historic significance attributed to the Victorian fabric thus resulted in an elevation of aesthetic value and justified more extensive replacement. Each component of the conservation project is hence the product of a specific amalgamation of expertise regarding condition and significance.

The masons' material interventions are specified in minute detail in documents and drawings and reiterated in site meetings. Photographs record evidence of deterioration and other problems. Elevation drawings detail graphically which remedial actions should be employed where. These are the product of thorough and measured procedures involving different forms of expertise. In this way, heterogeneous aspects of 
the Cathedral are stabilized helping to constitute the building as a site of physical intervention. The indents the masons are working on are thus a product of various forms of labour that precede and are imbricated in the impact of mallet and chisel. As we will see, they can also be re-activated at later stages in the micro-processes surrounding specific pieces of masonry. First, however, we turn to the central role of documentation in conservation practice.

\section{'Paper, Paper'}

Catherine, a senior manager introduced above, arrives late clutching a large ring binder, which she deposits with literal and metaphoric weight on the desk. Without pause, she begins to tell us about HS's conservation policy, making frequent reference to the documents that burst from her folder. 'Paper, paper', she remarks as she leafs through in a vain search for a particular document. As a visual image, it illustrates the wider role that paperwork performs in the conservation process: it is both a means by which heritage managers produce order, and an object that itself requires management. The folder is her 'bible', she says, an allusion that conveys the centrality of the documents it contains to all that she does.

'Paper', as a concrete manifestation of broader processes of documentation, has long been an element in conservation work, but in recent years there has been increasing emphasis on recording interventions. Kevin, an archaeologist by training, explains how this informs his role as Cultural Resource Advisor: 'my focus is on aspects such as authenticity [...] and recording anything that we replace or lose in the process'. In documenting interventions and their rationale, a 'paper trail' is created that enables differentiation between 'original' and 'repair', thereby allowing future generations to read authenticity. Susan, Head of HS’s Conservation Group, similarly explains:

We have to actually record why we're doing something [...] We've not been good at that in the past [...] Yes, I can find the mortar mix, and yes, I can find which stones were replaced, and you might even find a discussion about [why] this stone's very important. But actually why are we making this intervention wasn't always explicit.

Whether such documents take paper or digital form, they fix meanings and actions. In Latour's (1987) terms, such 'immutable mobiles' are central to the creation of managerial visibility. They attempt to extend a stable set of relationships over time and space, holding together otherwise disparate knowledge and information. Such documentation is also an attempt to stabilize an authentic object in the face of the jeopardy created by physical intervention (cf. Tait and While 2009: 734). Records of the monument before and after conservation act as a proxy for the thing itself and seek to mitigate the loss of original fabric in what is essentially an attempt to preserve by record.

The proliferation of documentation also reflects a broader 'audit culture' (Strathern, 2000) in which 'accountability' and 'transparency' lead to explication of previously implicit processes. Documentary practices have been heightened by an increased emphasis on regulating work at HS's Properties in Care. Legal consent is required for any work that impacts on scheduled monuments and this is subject to a 
rigorous process of application and assessment (HS 2009: 32-6). Consent provides a means of ensuring minimum levels of evidence-based intervention. It is seen as central to HS's role in protecting the nation's heritage and 'applying the brakes' to external parties. Yet, over the last decade there have been demands for similar forms of scrutiny and accountability regarding work on monuments in HS's care. In 2010, 'clearance' for such work (known as Properties in Care Clearance (PICC)) was approved by the Inspectorate and involved a rigorous process of internal application involving architects, cultural resource managers and, where appropriate, conservators. Glasgow Cathedral was not technically subject to PICC, because the above ground parts of the building are not part of the designated scheduled monument, but as a property in care it had been subject to the same clearance process up until 2010. In requiring that prospective interventions be described and justified, many acknowledge that the clearance process enables scrutiny and accountability. Tom, a senior member of the Cultural Resources Team and an archaeologist by training, describes the PICC process as 'completely auditable' in that 'the trail is there to follow'. The formal nature of the clearance process is also seen to lend decisions a degree of 'objectivity' and to facilitate an 'evidence-based' approach.

Yet, while the importance of formal processes of clearance and documentation are acknowledged, their shortcomings are also highlighted. Across a range of different forms of expertise there are reservations about how judgement and tacit knowledge are curtailed by processes of codification. Having worked for HS for over twenty years, Susan points out that 'there's never one answer' and attempts to codify practice have their limits:

You can't write a book that says every time you point it will look like this and you'll do this and this [...] It depends on the stone, it depends on the location, it depends how much of the building is left, it depends on the skill of the people doing it.

Her view that conservation is about 'judgement rather than rules' relates to a broader emphasis on 'experience'. By curtailing the 'judgement' and 'sensitivity' resulting from experience, paperwork can undermine sensitivity to the specificities of particular buildings. Graham, the District Architect responsible for the Cathedral, argues that no matter how much paperwork is produced, 'the building needs to be there with its own voice and views and that adds to the decision-making process immensely'. If too much is formalized and codified, the building's 'voice' becomes lost. Furthermore, he suggests that going 'too deep with the paper' negates the 'bit by bit process' of conservation:

Each stone, never mind each part of the building needs a different thought process because it's literally bit by bit, by bit, literally like building up a big painting with lots of dots and so you can't do it all on paper.

Heritage professionals thus acknowledge a tension between the positive and negative aspects of the clearance process. They emphasize the importance of 'balancing' paperwork with tacit understanding, to reconcile the demands of accountability with the judgement, experience and sensitivity required to protect a monument's authenticity. The question of where this balance should lie is contextual, but partly relates to different forms of expertise and different ways of working. Bruce, a senior 
conservation architect, explains that architects tend to work with a 'very graphic kind of presentation', with drawings and photographs, whereas in his view his colleagues focusing on cultural significance, who play a curatorial role, tend to 'want a lot of writing, a lot of prose'. His concern to see less paperwork is framed, in part, by a concern that documentation supersedes more intimate or tactile relationships:

Previously a lot of decisions were actually made on the scaffold looking at something. You know, you tap it [the stone], or you run a key across it, and you know from experience that that's breaking down [...]. It makes a different noise. Or as you touch it, it just sugars off in your hand [...] I think no one's actually convinced us that when you see something like that you necessarily need to go through three pages of appraisal.

Paper thus threatens to displace forms of judgement that emerge in practice through specific interactions between skilled experts and the material fabric of particular monuments.

The formalization of processes of documentation and clearance also has implications for the ways different forms of expertise are put to work. Bruce evokes an image of a vortex of paper surrounding the Cathedral, and asserts that it is the role of professionals to 'move all this paper around', so that 'these guys, these practical masons, who are the real fundamental base of everything, [can] get on and do their job'. In this image the collective expertise of 'professionals' is marshalled to manage 'bureaucracy' so that its effects on the 'real work' of the masons are minimized. At the same time, heritage professionals acknowledge that documentation can marginalize the expertise of masons. Susan speaks of the importance of the masons' knowledge describing it is a kind of 'folk memory'. In the past they were given considerable latitude, but now, she suggests, formal processes constrain their work: 'we're not leaving them leeway to make things, because we've had to document it'll be this stone, it'll be that big and we'll be using this mortar mix and you'll be doing it like that'. The question of how these specific micro-practices are negotiated and resolved is the question we turn to next.

\section{Fabric and Form}

'Let me just explain something further', says Tom, an archaeologist and member of the Cultural Resources Team, sketching a debate between himself and a now retired District Architect that took place on the scaffold at Glasgow Cathedral:

His contention was that once the face had gone the rest of the stone was of no value whatsoever. [...] And I argued completely the contrary. You know, to my mind the rest of the stone was still quarried in 1350, it's still that stone that was then taken to the site, that was cut, that was taken up a rickety wooden scaffold that lots of people had probably fallen off, had been dressed, given the final dressing and placed in the mortar bed, and was an integral component, therefore of the thing itself, of the thing that we are trying to conserve. Whereas from a technical architectural conservation view point, he was saying once the face of the stone [...] was lost, which is often the case, because of the erosion that's taken place at the Cathedral, the rest of the stone has no value. So that's it getting down to a micro-level. 
Their debate reiterates tensions that run through the history of conservation theory and philosophy (see Delafons 1997; Hernández Martínez 2008; Jokilehto 1999). The modern conservation movement, emphasising conservative repair and maintenance, emerged in reaction to the widespread practice of restoring historic buildings, especially ecclesiastical ones, in the early 19th-century. Restorers, such as Viollet-le-Duc, Salvin, Bodley and Gilbert Scott, aimed to recover the original design in its purest form. In the process, they engaged in radical reconstruction, removing later phases of construction and 'scraping' back the patina of age (Delafons 1997: 14). In response, the forebears of the modern conservation movement, such as John Ruskin and William Morris, stressed the material truth of historic architecture. Restoration, they argued, is 'a lie' involving the destruction of the unique authentic work, moulded by those associated with it and marked by the passage of time (Jokilehto 1999: 175). The importance of preserving authenticity through minimum, evidence-based intervention was subsequently taken up in various modified forms by influential architects, engineers and conservators, such as Camillo Boito, Gustavo Giovannoni and Cesare Brandi (Hernández Martínez 2008: 24951). It has also been enshrined in the international heritage instruments of ICOMOS and UNESCO, which inform an international authorized heritage discourse (Smith 2006).

Echoes of these historic disputes persist in the Ruskinian notion of historic witness evocatively rendered by Tom, in contrast to the District Architect's concern with the form, aesthetic value and significance of the dressed surface of a piece of ashlar masonry. Ultimately, such debates are about the truth or honesty of historic buildings, whether this is seen to inhere in their original 'pure' form and aesthetic characteristics, or alternatively in their material continuity over time (cf. Eggert 2009: 35). Such distinctions relate to different forms of expertise and ways of understanding the Cathedral. While all adhere to the basic tenets of minimum intervention, the ways in which these are practically interpreted and applied are inflected by distinct perspectives arising from different forms of expert practice. From an architectural perspective, the principle significance of stones inheres in their aesthetic and functional contribution to the structural whole. Bruce, the Regional Architect responsible for the Cathedral, highlights these ideas describing 'the way the eye rolls across the building' and hence 'how the building works as a whole'. By contrast those from archaeological and curatorial backgrounds suggest the architectural concern with aesthetic unity can negate appreciation of material integrity. Catherine, a heritage manager with a curatorial role, suggests this architectural approach can 'create something beautiful, but lose something amazing'. Locating authenticity in the very fabric of the stones, she is more inclined to prioritize the retention of material over aesthetic and functional concerns.

Ultimately, while these different visions inspire different kinds of intervention, in practice various forms of resolution and compromise must be achieved. Thus conservation policies, evaluations and formal processes of consent do not negate the need for informal dialogue and debate. Catherine was involved in the project from the start and describes the ongoing process of dialogue:

At each point where we're replacing something we stop and say: 'Do we have to? How are we going to do it? What's it going to look like?' So you don't just have the squad involved or the architects, [...] all of the skills that we bring to bear on 
the building actually stand on the scaffolding getting wet and cold at the same time.

Forms of expertise that are brought together in the Condition Survey and the Statement of Significance are re-activated, and also re-negotiated, in annual monument audits and regular meetings associated with the conservation programme. Such documents serve to stabilize heterogeneous aspects of the Cathedral, which threaten its coherence as an authentic object that can be subjected to conservation. Yet, the importance of 'teamwork' and 'dialogue' necessary to achieving consensus is stressed. Talking of the need for respect, actors with different forms of expertise and skill acknowledge the partiality of their own perspective. Furthermore, the physical presence of the building plays a critical role in achieving resolution. Alek, a mason and the Works Manager of the Cathedral Monument Conservation Unit, takes part in various on-site meetings and explains that abstract differences are frequently resolved through proximity to the Cathedral: 'When you're all looking at the problem right then, you with me, that's it.' Being co-present allows different visions of the building to be contextually aligned, to produce a singular plan for intervention from the range of possibilities. It is not simply that the building creates a context for discussion and debate. The Cathedral is a material embodiment of different agencies with distinct temporal trajectories, including Medieval and Victorian masons, representatives of the Catholic and Protestant Churches, various architects and conservation professionals. Hence interventions arise neither from the subjective actions of people in the present, nor from the objective properties of the Cathedral, but rather in the complex interplay between a range of people and things enjoined in a complex nexus of action.

Nevertheless, the sense of jeopardy resulting from actions that raise fundamental questions about honesty and truth can make this a fraught and complex process. In cases where decaying masonry must be replaced 'evidence' is a crucial lynchpin, anchoring new interventions to the historical fabric and thus facilitating a migration of authenticity to the new material (c.f. Latour and Lowe 2011). Yet evidence itself is often compromised. The structurally unsound remains of a gargoyle, for which very little evidence survives, highlights the issues at stake. For Kevin, a member of the Cultural Resource Team with archaeological training, the notion of a reconstruction creates considerable unease, because of the potential to confuse the evidence embodied in the building. He therefore advocated replacing the original with an uncarved block of stone (a technique specified in HS 2001: 21), so as to literalize the absence of evidence, allowing future generations to 'read' the building, distinguishing 'original' from 'replacement'. In contrast, the architects and masons proposed a reconstruction in a 'sympathetic contemporary style', arguing that this would carry forward the 'longstanding tradition' whereby masons 'add evidence'. Emphasizing aesthetic unity, Bruce, a senior conservation architect, expresses great unease about a rough-hewn block of stone: 'the thought of the eye running across three [gargoyles] - a face, a face ... my god! What the hell's that? [laughs] That was completely unpalatable'. The District Architect, Graham, conveys similar disdain for 'some sort of Gaudiesque eroded weird thing [that's] actually detracting from the architecture of the building'.

In the solution that emerged, a senior mason carved a new gargoyle drawing on appropriate examples from Glasgow and other Cathedrals (Figure 6); a compromise that in the words of Kevin 'uses some of the evidence', but is also 'slightly a 
reinterpretation'. Crucially, the tenuous nature of the evidence is counterbalanced by the idea that authenticity can be accrued through the involvement of the masons, as embodiments of a craft tradition, who can carve a new gargoyle just as 'medieval masons would have'. Thus, in the face of differing interpretations of common policy frameworks, evidence is combined with interpretation to produce a contextually specific resolution of a wider tension between material and aesthetic understandings of authenticity.

\section{'Stone is Stone'}

Robbie, the site apprentice is 17 with a fashionable asymmetric haircut and youthful confidence. Both draw the other masons' scorn. Though they treat 'the boy' with avuncular care, he is the butt of most jokes. There is one in particular that they like to tell on site 'Hey what do you know? Stone's been cut the same way for 1500 years but Robbie's found a new way!' It always gets a laugh. The point, as John explains, is that stone can only be cut one way; there are no new ways, only the right and the wrong way. The joke underscores the essential paradox that cutting stone involves learning a set of enduring principles that are simple to understand, but immensely difficult to apply; they can be taught in a morning, but take a 'lifetime's learning'. Furthermore, these principles are integral to ways of seeing and acting, which allow masons to produce interventions that are 'right' and 'true'.

The nine men comprising the Cathedral Monument Conservation Unit have distinct roles, relating to different forms of skilled practice. At the top of a tacitly acknowledged site hierarchy, the 'banker' masons cut stone, which is 'fixed' into the building with the assistance of others (Figure 7). Although some were trained in commercial contexts, all are familiar with conservation ideals and take pride in doing work that is finely-tuned to the idiosyncrasies of historic buildings. However, their work is embedded in principles of stonemasonry that generate different ideas of authenticity than those discussed so far. The act of cutting stone is tacitly regulated by a set of principles and practices that masons locate in a long tradition. As John, a senior mason in the squad, asserts in reference to medieval masons: 'The way they done it, is the way we do it.' Claiming that 'stone is stone', he underlines the unchanging nature of the craft, seeing his own work as part of an 'unbroken chain' going back to the Egyptians. The authenticity or 'truth' of the practice of masonry thus inheres in a profound sense of connection, repeating the same actions in the same place.

This 'chain' of tradition is produced by adherence to an inviolable set of principles. The new indent must be cut and fixed as the stone was laid, that is, with the bedding plane lying horizontal. The stone is roughed out and 'squared off', using mallet point, tooth comb and finally chisel. It is then shaped using 'checks' and 'splays'. Since these principles can be used to work the stone into any shape, a finite range of principles contains infinite formal possibilities. Yet if knowing the principles is held to be easy, acquiring the skill to apply them is an un-ending task. In part this is because historic buildings are irregular and constantly throw up new challenges. It is also because sticking to these principles requires the acquisition of various personal traits, including 'discipline' and 'patience' (see Jones and Yarrow, forthcoming). 
'Fixing', the act of inserting new indents of stone in the building, also involves adherence to enduring principles of construction concerning the forces at work in the relationships between architectural elements. Ally, the main fixer mason, explains, 'you've got to keep thinking loads all the time'. Through calculating how 'side' and 'down' loads are affected by the removal and replacement of stone, he calculates what needs supporting or pinning. Fixing also requires that stones are 'plumb' and 'level'. These understandings become part of an instinctive and 'natural' way of looking that is central to achieving a 'true' repair.

Pointing also entails forms of skilled practice, partly circumscribed by the results of scientific investigations. Based on chemical analysis of original materials, lime mortar recipes are produced, which replicate the hydraulic and aesthetic characteristics of the medieval mortar and allow the building to 'breathe'. Pointing takes place in stretches to prevent discrepancies in colour and help the mortar blend in. As the material 'cures', it is brushed and washed to prevent cracking and crusting. The skill of such practices lies in the ability to elicit specific material and aesthetic potentialities latent in the substances that are combined.

By contrast to the heritage professionals that work for HS, masons do not talk explicitly about 'authenticity'. Yet semantic relationships are set up through the ideas of 'honesty' and 'truth' that inform their work. For masons, a repair is honest where it conforms to the principles of masonry. Angus, one of the banker masons, recounts an apocryphal story that illustrates this idea. An 'old school' mason had been asked to build a wall to fill a gap between two older walls. 'So he built up his wall, his was true, right plumbed in, bang on, plumbed. And the gaffer came down and said, "oh what's happened here?", because the two existing walls at the either side were away back.' The boss asked him to rebuild it, but the mason refused, 'you're asking me to do it wrong' he said 'and a stonemason is only true as his square'. Because of its irregular qualities, the Cathedral poses similar dilemmas for the masons, who frequently have to reconcile the 'truth' of their principles, with the vagaries of the existing structure. Decisions have to be made as to whether replacement stone should be 'sweetened in' with the existing structure, or 'honestly' repaired according to the principles of masonry.

Shared understandings of the principles of authenticity and minimum intervention frame contextual differences of perspective with respect to specific contexts. Amongst the masons differences sometimes emerge between those with greater conservation training who often emphasize 'sensitivity' to the building and 'sweetening in', and those originally trained in commercial contexts. More commonly, the masons' collective desire to produce 'honest' and 'true' repairs runs up against curatorial perspectives, expressed most strongly by the HS Cultural Resource Team, whose overriding concern to preserve historic fabric leads to a stricter interpretation of minimum intervention. Such differences of approach arise more fundamentally in different ways of relating to the building and its temporality. While the logic of 'conserve as found' ultimately seeks to extract historic monuments from temporal processes, conservation practices themselves ensure that they continue to change and develop, acquiring new meanings and values as they do so. This paradox frames the debates surrounding particular conservation problems, which in turn are partly inflected by different traditions of expert practice. Though stonemasons and architects relate to the Cathedral in qualitatively different ways, both situate themselves as part of 
its history, viewing their work as part of a longer process of construction and repair. One mason proudly explains, 'what we do will be history'. Bruce, one of the senior architects, similarly stresses the 'warming' sense of 'being part of a tradition'. Here, continuity of practice is related to a notion that intervention itself remains a constant, and thus authentic, aspect of the building's life. At times this vision is at odds with those who play a curatorial role and seek to define and stabilize significance. Tom, Head of Cultural Resources, suggests that 'history should stop with [buildings] coming into care' and they are 'not places we can add to'. In their endeavour to preserve material authenticity, evidence and significance, curators work towards the suspension of time by attempting to arrest material change (cf. Bell 2011: 226). In turn they deal with the paradox of intervention by situating their own work 'outside' of history, in contrast to the masons and architects who see their labour as part of the flow of time (cf. Herzfeld's distinction between 'monumental' and 'social time' (1991)).

Different visions of authenticity and time also intersect with issues surrounding the use of tools (Jones and Yarrow forthcoming). The mechanization of production has been integral to debates about conservation since the nineteenth century. For Ruskin and Morris, the mechanical age destroyed the intimate relationship between the artisan or craftsman and his work (Sennett 2008: 108-9). Equally it undermined the naturalistic qualities, rough-hewn beauty and noble character of the craftsman's work, which could be found in an idealized form in the great medieval Gothic buildings (ibid.). Many of the modern principles of heritage conservation, focusing on minimum repair and maintenance, emerged from a concern to preserve these qualities. As part of the Romantic rejection of mechanized production, the Society for the Protection of Ancient Buildings (SPAB) aimed to support traditional building crafts, with an emphasis on hand tools and techniques and traditional materials (Hassard 2009: 277-8). Conservation of historic buildings was as much a means to conserve traditional intangible craft skills as vice versa (ibid.).

Tools remain a potent source of anxiety with respect to differing conceptions of authenticity. Conservation architects and archaeologists in HS stress that hand tools offer a 'traditional' finish, alluding to the kind of naturalistic qualities that Ruskin so desired. Their ideas also resonate with Romantic ideals, seeing hand tools as a source of continuity and the basis of a 'living tradition'. Masons articulate similar concerns, equating hand tools with a slower, more patient way of working, symbolic of the essence of stonemasonry. This understanding sets up an implicit hierarchy of practice: while power tools, such as saws, drills and grinders, are used in preparatory work, such as 'roughing out' stone, they are practically and conceptually separated from the end result. John, an experienced banker mason, explains that grinders are 'just there to take down the weight...everything is done by chisel at the end.' The desire to separate machines from work incorporated into the building echoes the concerns of Morris and Ruskin. Yet, power tools are not inauthentic per se. Emphasizing continuity through change, masons stress that medieval masons also worked with 'the best available tools'. At issue is the capacity of different tools to extend or alternatively curtail the principles masons place at the heart of their craft. As such they are critical of what they see as a misplaced reification of hand tools as synonyms of 'authentic tradition'.

For the masons, authenticity is thus expressed through notions of honesty and truth that ultimately depend upon adherence to the enduring principles of 
stonemasonry. These principles tie the masons into a tradition, which, in their view, allows them to add to the building in an authentic manner, their labour becoming part of its history. Inevitably this understanding runs up against the notion of the building as evidence, or historical document, extracted from time. Indeed, it activates the central paradox at the heart of conservation: how to keep something 'the same' while changing it. Much effort is devoted to resolving the resulting tensions, ranging from moderation of the masons' enthusiasm for intervention, to the marshalling of evidence and the exhaustive documentation of new work. Self-documenting techniques, such as the use of date marks and different kinds of finish, are particularly important in curatorial terms (Figure 8). These have a venerable place in the history of conservation, being closely associated with the philosophy expounded by William Morris's SPAB, and their principle purpose is to ensure readability by differentiating new work from historical material. Thus while the practices of stonemasonry are oriented towards producing authenticity through continuity between past, present and future, curatorial practices simultaneously operate to extract the current conservation work from the stream of time.

\section{Conclusion: authenticity as distributed practice}

We have suggested that heritage conservation entails a number of paradoxes stemming from the underlying problem that securing the past 'as it is' necessarily involves accepting some forms of intervention and change. Through an ethnographic study of heritage conservation we have explored how various actors confront and resolve these problems, however contingently, with a subtlety and reflexivity that is often neglected in theoretical critiques of policy discourse. In particular, we have illustrated how authenticity is 'crafted' through different forms of expert practice. Tracing the different forms of expertise that mediate heritage conservation shows that there are different views of the building, but more profoundly there are also different ways of enacting the Cathedral as an object of intervention. Different expert practices, mediated by specific tools and materials, literally create different objects of attention, for instance through drawing, documentation, stone cutting and various other forms of 'skilled vision' (cf. Grasseni 2007; Mol 2002). Distinct forms of specialist knowledge do not simply exist as different 'perspectives', but rather reside in the differing techniques at their disposal: a hammer and chisel literally offer different points of leverage to a pen and paper. Through conservation the Cathedral, and its authenticity, is thus literally formed through the intersecting practices of heterogeneous actors (cf. Tait and While 2009).

As those involved in heritage conservation acknowledge, such differences sometimes lead to tensions and disagreements. Conservation practitioners work within common conceptual frameworks, deriving from international and national heritage policies, and share a concern with 'the wholeness, the realness, the truthfulness of the site on which they work' (Stovel 1995: 396). However, as Bell (2011) shows for resident experts and professionals involved with the Grade II* listed Spa Green housing estate, mutual investment in the need to maintain authenticity masks different views about where it resides and how it can best be maintained. In their curatorial role, HS's Cultural Resource Team are particularly attuned to the notion of the building as historic witness and as a document that embodies evidence. As such, they tend to advocate the preservation of the Cathedral's fabric, unless this places its structural integrity in jeopardy. Masons, by contrast, see themselves as part of an 'unbroken chain', locating 
authenticity in an enduring tradition of cutting stone that engenders a different, more interventionist, duty of care. Architects bring an emphasis on the design of the building and the rationale behind its architectural components, which can lead them to privilege wider form and function over individual stones and historic fabric. Expert practices thus draw people into different relationships with overarching policy frameworks and conservation philosophies. In attempting to keep the building 'as it is', some emphasize form, while others privilege material and fabric. By the same token, different views are produced about what constitutes 'minimum intervention'. In this way broader philosophical debates, including those of central concern to nineteenth century conservation thinkers, are refracted through the lens of specific expert practices with respect to the particular material contexts.

In their studies of conservation and maintenance, Tait and While (2009) and Edensor (2011) argue that conservation ethics are founded on an ontology of buildings as stable, unified objects. Arguing on the contrary that buildings are formed from assemblages of materials and agencies that are continually made and unmade, they suggest that the objectives of conservation need to be rethought. While our research largely accords with their theoretical position, we question the implication that conservation practice is entirely contained within this essentialist ontology. In our research, conservation emerges as an inherently complex process in which practitioners grapple with the stability and instability of the monuments and buildings they work with. International conservation instruments and national policy documents may presuppose an ontology of monuments and buildings as stable unified objects of intrinsic value. However, unruly forces of erosion and deterioration, as well as complex histories of modification and former campaigns of conservation, provide sources of instability and disorder that practitioners are acutely aware of. Indeed it can be argued that conservation practice creates a space in which the multiplicity and instability of the object of conservation is exposed and negotiated. While our paper therefore builds on Edensor and others in highlighting a degree of fluidity overlooked in more essentialist visions of authenticity, we also wish to highlight the ethnographic sense in which stabilization emerges as a central, if problematic, concern.

Intervention produces a shared sense of jeopardy that underpins mutual recognition of the need to act with balance, judgement and sensitivity. Practitioners seek to guarantee the authenticity of maintenance, repair and reconstruction by anchoring it to the past, even if they enact this in different ways. Curators deploy evidence and documentation, architects produce drawings that emphasize overall continuity of form and design, and masons look to skilled practices of cutting and fixing as an intangible thread of continuity. These different techniques for securing authenticity often co-exist alongside one another, but tensions arise when they suggest incommensurable outcomes. Most profoundly, tensions surround the temporal location of conservation practice 'in' or 'out' of history. In the former vision, conservation work can be seen as part of the stream of time, and the weight of tradition provides the means to anchor contemporary interventions to an 'authentic' past. In the latter perspective, the notion that historic fabric embodies actions and ideas from the past relates to an emphasis on authenticity as a material property. Accordingly, curatorial effort is expended maintaining a 'light touch' and ensuring the 'reversibility' of interventions. 
It is clear then that the principles and assumptions making up the discursive nexus of conservation are differentially distributed. Shared understandings are contingent outcomes of the application of specific forms of expertise and skilled practice to particular material contexts rather than their precondition. Relationships between people involving judgement, balance, teamwork and trust are seen to be important in resolving different forms of expertise to produce a coherent basis for intervention. However, material conditions, in this case the nexus of materials that constitute the Cathedral, also play a crucial role. Distinct forms of expert knowledge and skilled practice are refracted through specific material contexts, as articulated by the image of different forms of expertise and skilled practice coming together on the scaffold. Thus, authenticity is neither a subjective, discursive construction, nor a latent property of historic buildings and monuments waiting to be preserved. Rather it is a distributed property that emerges through the interaction between people and things.

\section{Acknowledgements}

This research was supported by a British Academy Small Grant (Ref. SG100577). We are grateful to HS for granting permission for the research. We would like to express our heartfelt thanks to those members of the Conservation and Maintenance Group and the Cultural Resource Team, who participated in interviews. In particular, we are indebted to the Glasgow Cathedral Monument Conservation Unit: Johnnie Clark; Scott Clark; Dave Kerr; Fraser Maxwell; James McGurk; Joseph McKee; Eric Ramsey; Jamie Rose; Joseph Ward. They shared their thoughts, expertise and working environment with us and without their generosity and interest the project would not have been possible. Many thanks also to our anonymous peer reviewers for their suggestions and to Matt Candea, Chantal Conneller, Stuart Jeffrey, Anna Karlström, Triinu Mets; Sharon Macdonald and Gregor Stark for their comments on earlier drafts of this paper.

\section{References}

Bell, Dorothy (1997) The Historic Scotland Guide to International Conservation Charters. Edinburgh: HS.

Bell, Harriet (2011) 'Listing, 'significance' and practised persuasion at Spa Green housing estate, London', Social \& Cultural Geography 12(3): 223-42.

Bracker, Alison and Alison Richmond 2011. 'Introduction', in Alison Richmond and Alison Bracker (eds) Conservation: Principles, Dilemmas and Uncomfortable Truths, pp. xiv-xviii. London: Routledge (2 ${ }^{\text {nd }}$ Edition).

Brajer, Isabelle (2011) 'The concept of authenticity expressed in the treatment of wall paintings in Denmark', in Alison Richmond and Alison Bracker (eds) Conservation: Principles, Dilemmas and Uncomfortable Truths, pp. 84-99. London: Routledge (2 ${ }^{\text {nd }}$ Edition).

Clavir, Miriam (2002) Preserving What is Valued: Museums, Conservation and First Nations. Vancouver: UBC Press.

Clavir, Miriam (2011) 'Conservation and cultural significance', in Alison Richmond and Alison Bracker (eds) Conservation: Principles, Dilemmas and Uncomfortable Truths, pp. 139-49. London: Routledge ( $2^{\text {nd }}$ Edition). 
Delafons, John (1997) Politics and Preservation. London: Chapman and Hall.

Edensor, Tim (2011) 'Entangled agencies, material networks and repair in a building assemblage: the mutable stone of St Ann's Church, Manchester'. Transactions of the Institute of British Geographers 36: 238-252.

Eggert, Paul (2009) Securing the Past: Conservation in Art, Architecture and Literature. Cambridge: Cambridge University Press.

Grasseni, Cristina (2007) Skilled Visions: Between Apprenticeship and Standards. New York and Oxford: Berghahn Books.

Hassard, Frank (2009) 'Intangible heritage in the UK', in Laurajane Smith and Natsuko Akagawa (eds) Intangible Heritage, pp. 270-88. London: Routledge.

Herzfeld, Michael (1991) A Place in History: Social and Monumental Time in a Cretan Town. Princeton: Princeton University Press.

Hernández Martínez, Ascensión (2008) 'Conservation and restoration in built heritage: a Western European perspective', in Brian Graham and Peter Howard (eds), The Ashgate Research Companion to Heritage and Identity, pp. 245-266. Aldershot: Ashgate.

HS (2000) The Stirling Charter. Edinburgh: HS.

HS (2001) The Conservation of Architectural Ancient Monuments in Scotland: Guidance on Principles. (Prepared by R. Fawcett.) Edinburgh: HS.

HS (2005a) Glasgow Cathedral: Interim Statement of Cultural Significance (Prepared by P. Yeoman). Unpublished report.

HS (2005b) Glasgow Cathedral: Condition Survey and Conservation Strategy (Prepared by Ian Lambie). Unpublished report.

HS (2009) Scottish Historic Environment Policy. Edinburgh: HS.

Holtorf, Cornelius and Tim Schadla-Hall (1999) 'Age as Artefact: On Archaeological Authenticity', European Journal of Archaeology 2(2): 229-47

ICOMOS (1964) The Venice Charter.

ICOMOS (1979) [revised 1999] The Burra Charter: The Australia ICOMOS Charter for Places of Cultural Significance.

Jokilehto, Jukka (1999) A History of Architectural Conservation. Oxford: ButterworthHeinemann.

Jacobs Jane M. and Peter Merriman (2011) 'Practising architectures', Social \& Cultural Geography 12(3): 211-22.

Jones, Siân (2010) 'Negotiating authentic objects and authentic selves: beyond the deconstruction of authenticity', Journal of Material Culture 15(2): 181-203.

Jones, Siân and Thomas Yarrow (forthcoming) Craft as Detached Engagement: an Ethnography of Stonemasonry. Submitted to American Anthropologist.

Latour, Bruno (1987) Science in Action. Cambridge, Mass.: Harvard University Press.

Latour, Bruno and Adam Lowe (2011) 'The Migration of the Aura, or How to Explore the Original Through its Facsimiles', in Thomas Bartscherer (ed.) Switching Codes, pp. 27598. Chicago: University of Chicago Press. 
Lowenthal, David (1992) 'Authenticity? The Dogma of Self-Delusion', in Mark Jones (ed.) Why Fakes Matter: Essays on the Problem of Authenticity, pp. 184-92. London: British Museum Press.

Mol, Anne-Marie (2002) The Body Multiple: Ontology in Medical Practice. London: Duke University Press.

Muñoz Viñas, Salvador (2011) 'Minimal intervention revisited', in Alison Richmond and Alison Bracker (eds) Conservation: Principles, Dilemmas and Uncomfortable Truths, pp. 47-59. London: Routledge (2 ${ }^{\text {nd }}$ Edition).

Philippot, Paul (1996) 'Historic preservation: philosophy, criteria, guidelines', in Nicholas Stanley Price, Talley M. Kirby and Alessandra M. Vaccaro, (eds) (1996) Historical and Philosophical Issues in the Conservation of Cultural Heritage, pp. 268-74. Los Angeles: The Getty Conservation Institute.

Pye, Elizabeth (2006) 'Authenticity Challenged? The 'Plastic House' at Çatalhöyük', Public Archaeology 5: 237-51.

Pye, Elizabeth and Dean Sully (2007) 'Evolving challenges, developing skills', The Conservator 30(1): 19-37.

Ruskin, John (1865) The Seven Lamps of Architecture. New York: John Wiley and Sons Sennett, Richard (2009) The Craftsman. St Ives: Penguin.

Smith, Laurajane (2006) The Uses of Heritage. London: Routledge.

Strathern, M. (2000) 'Introduction: new accountabilities', in Marilyn Strathern (ed.) Audit Cultures: Anthropological Studies of Accountability, Ethics and the Academy, pp. 118. London: Routledge.

Strebel, Ignaz (2011) 'The living building: towards a geography of maintenance work', Social and Cultural Geography 12(3): 243-62.

Stovel, Herb (1995) 'Considerations in Framing the Authenticity Question for Conservation', in Knut E. Larsen (ed.) NARA Conference on Authenticity in Relation to the World Heritage Convention, pp. 393-8. Paris: ICOMOS.

Tait, Malcolm and Aidan While (2009) 'Ontology and the conservation of built heritage', Environment and Planning D: Society and Space 27: 721-37.

Villers, Caroline (2004) 'Post minimal intervention,' The Conservator 28(1): 3-10.

Yarrow, Thomas (2011) Development Beyond Politics: Aid, Activism and NGOs in Ghana. Basingstoke: Palgrave Macmillan.

\section{Illustrations}

Figure 1: Tourists approaching the south entrance of Glasgow Cathedral

Figure 2: A temporary display board erected by HS to explain the conservation programme.

Figure 3: Glasgow Cathedral from the south. 
The final, definitive version of this paper has been published in Journal of Material Culture 18(1) (2013), pp. 3-26, by SAGE Publications Ltd, All rights reserved. (C) Siân Jones and Thomas Yarrow

Figure 4: One of the 'banker' masons at work cutting a replacement finial.

Figure 5: New indents replacing decayed stone on the East elevation of the Cathedral.

Figure 6: The reconstruction gargoyle in the process of being carved.

Figure 7: 'Banker' masons at work.

Figure 8: A date mark, an example of a self-documenting technique. 